This item was submitted to Loughborough's Research Repository by the author.

Items in Figshare are protected by copyright, with all rights reserved, unless otherwise indicated.

\title{
Microstructure evolution and microhardness analysis of metastable beta titanium alloy Ti-15V-3Cr-3Al-3Sn consolidated using equal-channel angular pressing from machining chips
}

\section{PLEASE CITE THE PUBLISHED VERSION}

https://doi.org/10.1007/s11665-020-04913-8

\section{PUBLISHER}

Springer

\section{VERSION}

AM (Accepted Manuscript)

\section{PUBLISHER STATEMENT}

This is a post-peer-review, pre-copyedit version of an article published in Journal of Materials Engineering and Performance. The final authenticated version is available online at: https://doi.org/10.1007/s11665-020-049138.

\section{LICENCE}

CC BY-NC-ND 4.0

\section{REPOSITORY RECORD}

Shi, Q, Yau Tse, and Rebecca Higginson. 2020. "Microstructure Evolution and Microhardness Analysis of Metastable Beta Titanium Alloy Ti-15v-3cr-3al-3sn Consolidated Using Equal-channel Angular Pressing from Machining Chips". Loughborough University. https://hdl.handle.net/2134/14101883.v1. 


\title{
Solid consolidation recycling of metastable beta titanium alloy Ti- 15V-3Cr-3Al-3Sn from machining chips
}

\author{
Q. Shi ${ }^{a, b, *}$, Y. Y. Tse ${ }^{b}$, R. L. Higginson ${ }^{b}$ \\ a Guangdong Institute of Materials and Processing, Guangzhou, 510650, China \\ ${ }^{b}$ Department of Materials, Loughborough University, Loughborough, United Kingdom
}

\begin{abstract}
Solid consolidation recycling of metastable beta titanium alloy Ti-15V-3Cr-3AI-3Sn from machining chips by using back pressure assisted equal channel angular pressing (BP-ECAP) under different processing conditions were carried out. Nearfully dense specimens could be achieved after multiple passes at $500{ }^{\circ} \mathrm{C}$ with the aid of back pressures. Microstructure analysis by SEM and TEM shows that ultrafine equiaxed a grains $(\sim 180 \mathrm{~nm})$ formed in the $\beta$ matrix homogeneously as a result of extensive dislocations, vacancies and sub-grain boundaries generated during ECAP. Random orientation relationship between $\alpha$ grains and $\beta$ matrix was observed in most area. In addition, grain refinement, the increase in dislocation density and age hardening are suggested to response to the hardness enhancement in the consolidated Ti-15V-3Cr-3Al-3Sn samples. The microhardness homogeneity is improved with the processing temperature and the number of passes.
\end{abstract}

\section{Keywords}

Ti-15V-3Cr-3Al-3Sn; consolidation; equal channel angular pressing; ultrafine-grained materials; precipitation; 


\section{Introduction}

Metastable beta titanium alloys have been widely used in structural applications where high specific strengths, low elastic modulus, sufficient fatigue life, excellent corrosion resistance, deep hardenability and good cold formability and good biocompatibility are required ${ }^{[1-3]}$. These alloys contain enough quantities of $\beta$ stabilizing elements in order to ensure a fully $\beta$ phase body centred cubic microstructure is retained at room temperature after quenching from the singlephase field. The quenched alloys are thermodynamically unstable, heating the material to a sub-transus temperature leading to the formation of a precipitation. By aging process, the alloys can be strengthened by $50-80 \%{ }^{[4]}$. Ti-15V-3Cr-3Al-3Sn, as one of the most widely used commercial metastable beta $\mathrm{Ti}$ alloys, was firstly developed in 1970s as an alternate for Ti-6Al-4V especially in form of sheet components in aerospace industry ${ }^{[5]}$.

In industrial production, machining is one of the inevitable processes used for manufacturing Ti components with a complex profile. During machining process, up to $80 \%$ of raw material may be removed in the form of machining chips by using conventional manufacturing methods, such as turning, drilling and milling [6]. Traditional $\mathrm{Ti}$ recycling methods that involve re-melting and re-casting are usually high-temperature required and energy-intensive. Furthermore, high capital cost, for example thermal plasma furnace ${ }^{[7 ; 8]}$, is always necessary for Ti recycling due to its high propensity of reacting with air above $600{ }^{\circ} \mathrm{C}$. Compared to the traditional methods, solid-state recycling has the advantages of being processed at relatively low temperature and low energy consumption, and hence highly desirable.

Severe plastic deformation (SPD) techniques have developed over the last decade providing an efficient approach to manufacture bulk ultrafine-grained (UFG) materials [9-12]. Amongst SPD methods, equal channel angular pressing (ECAP) is considered as the most prospective one, thanks to its capability of imposing high shear strain on the work-piece without changing the cross-sectional dimensions [11]. Early researches have widely reported that metals and alloys possess superior mechanical properties [13-15] and enhanced corrosion resistance [16] after ECAP. Recently, the applicability of ECAP has been expanded to the recycling of metals and alloys from 
machining chips, from relatively soft metals and alloys, such as $\mathrm{Al}{ }^{[17 ; 18]}$ and $\mathrm{Mg}{ }^{[19}$; ${ }^{20]}$, to hard-to-work materials, such as $\mathrm{Ti}^{[21 ; 22]}$ and its alloys ${ }^{[23-25] .}$

The present work aims to give a systematic investigation on Ti-15V-3Cr-3Al-3Sn recycled from machining chips by using back pressure assisted ECAP (BP-ECAP). In particular, the relative density, microstructure evolution and microhardness after ECAP processing were analysed and demonstrated.

\section{Materials and experimental procedures}

In the present study, the bulk Ti-15V-3Cr-3Al-3Sn alloy was supplied by GfE-Metalle and Materialine $\mathrm{GmbH}$ in Nuremberg Germany in form of a round bar with diameter of $80 \mathrm{~mm}$. The raw material was in solution treated condition. The microstructure consisted of equiaxed coarse $\beta$ grains, as shown in Fig. 1(a). The machining chips were obtained by using conventional turning. In order to avoid contamination, coolant and lubricant were not used during the machining process. As shown in Fig. 1(b), the microstructure of the chips consisted of un-deformed matrix (region A) and severely deformed shear zones (region B). The ultrafine grained microstructure in the shear zones has been characterized in detail in our previous paper [26].
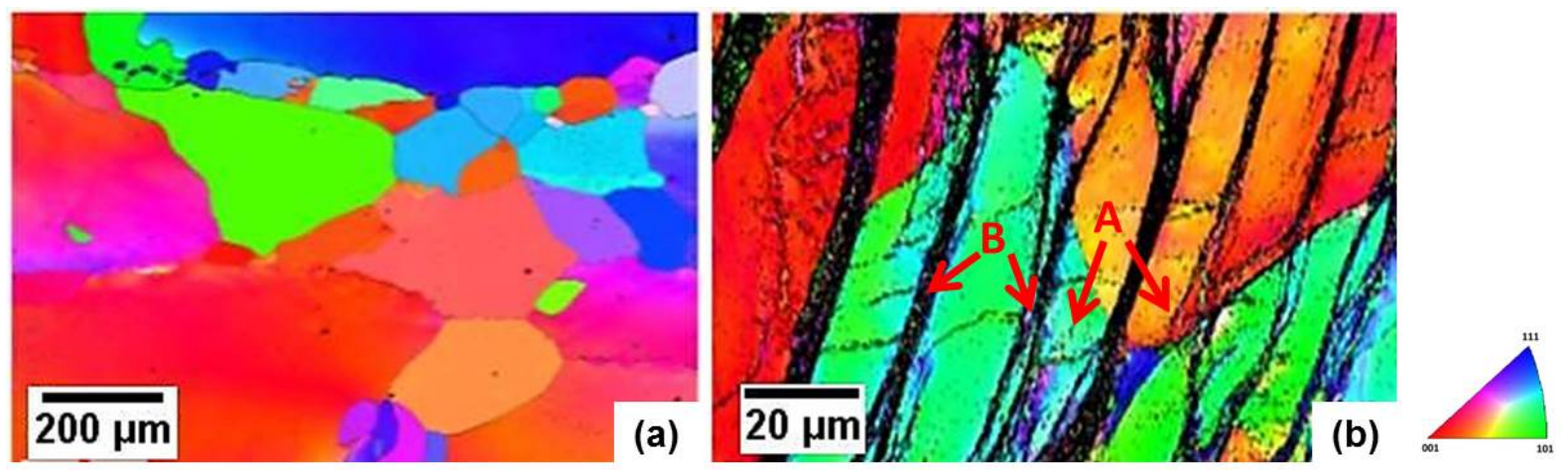

Fig.1 EBSD maps of (a) raw material and (b) machining chips ${ }^{[26]}$.

The set-up for the ECAP with back pressure, as shown in Fig. 2, has been described elsewhere ${ }^{23]}$, but briefly, the die has two channels of $10 \times 10 \mathrm{~mm}$ cross section with the intersection angle $(\phi)$ and the relief angle $(\psi)$ of $90^{\circ}$ and $\sim 36^{\circ}$, respectively, which leads to an imposed strain of $\sim 1$ per pass. All multiple pressings were conducted via route $\mathrm{B}_{\mathrm{c}}$, i.e. samples were rotated by $90^{\circ}$ in the same sense around the extrusion direction between each pass. The ECAPs were carried out at 
temperatures ranging from $400-500^{\circ} \mathrm{C}$ and with back pressures of $50-150 \mathrm{MPa}$. The samples were lubricated by $\mathrm{MoS}_{2}$ and pressed at a constant speed of $4 \mathrm{~mm} / \mathrm{min}$.

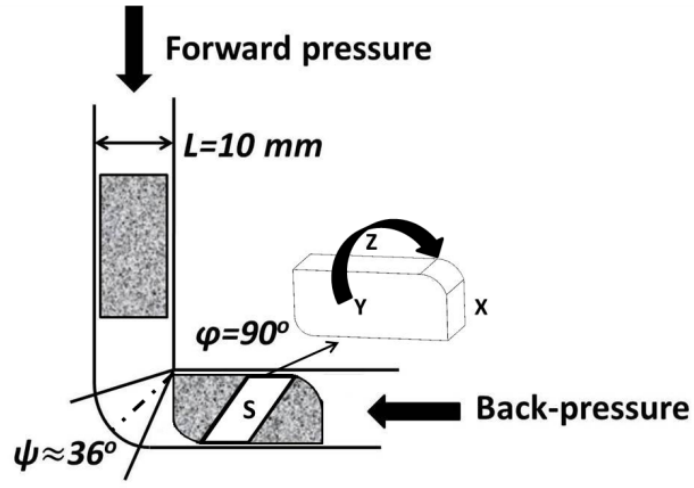

Fig. 2 Schematic diagram of the employed ECAP set-up ${ }^{[23]}$

The relative density was measured by Archimedes method. The microhardness mapping was conducted in DuraScan-70 hardness tester on the flow plane (longitudinal direction - extrusion direction plane) using a load of $1 \mathrm{kgf}$ with a spacing of $0.3 \mathrm{~mm}$ between each indentation. The samples for scanning electron microscopy (SEM) analysis were prepared by standard metallographic techniques finished by polishing with a solution of $80 \%$ colloidal silica $+20 \%$ hydrogen peroxide. Transmission electron microscopy (TEM) investigation was performed using JEOL 2000FX and FEI TECNAI F20 microscopes operating at $200 \mathrm{kV}$. Discs with diameter of $3 \mathrm{~mm}$, sliced parallel to the flow plane were mechanically polished to a thickness of $\sim 100 \mu \mathrm{m}$. The thin wafers were then perforated by argon ion milling (Gun current: $2.6 \mathrm{~mA}$, voltage: $7 \mathrm{kV}$ and inclination angle: $\pm 10^{\circ}$ ).

\section{Results and discussion}

\subsection{Relative density}

The variation of the relative densities for single-pass samples as a function of imposed back pressure at various temperatures is illustrated in Fig. 3. It is evident that the relative densities increased with the processing temperatures and imposed back pressures. The maximum relative density of $\sim 99.1 \%$ was achieved at $500{ }^{\circ} \mathrm{C}$ with a back pressure of $150 \mathrm{MPa}$. 


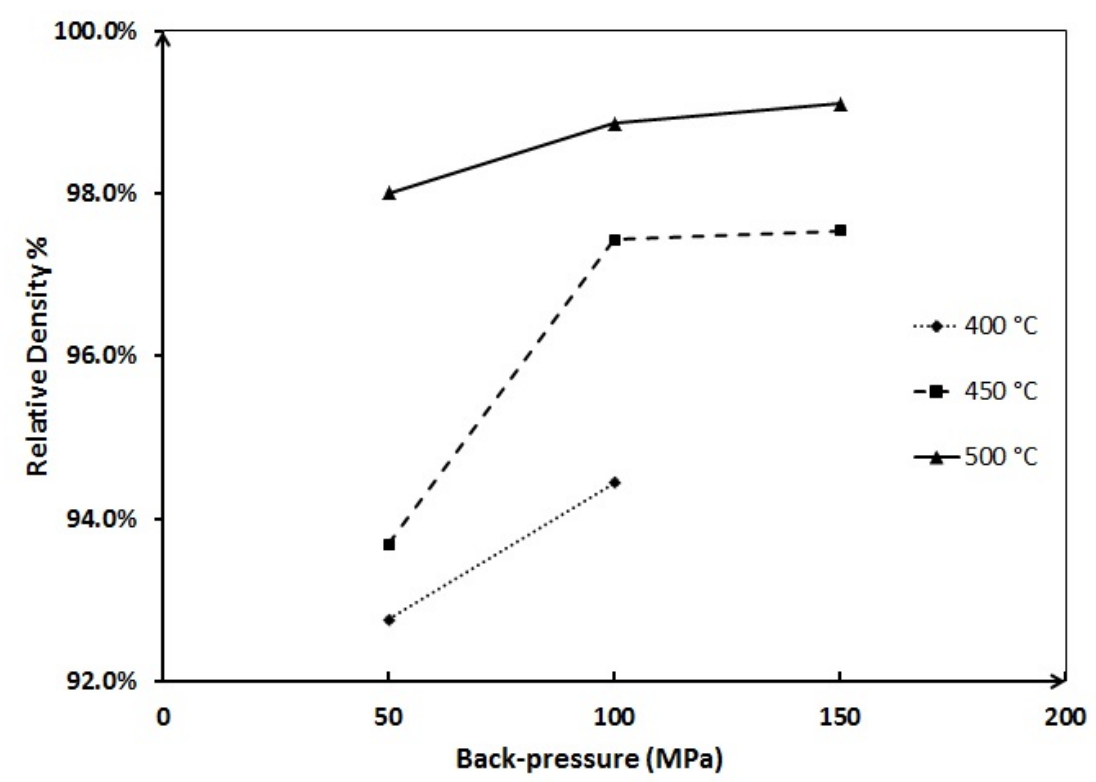

Fig. 3 Relative densities as a function of imposed back pressure at various temperatures for singlepass recycled Ti-15V-3Cr-3Al-3Sn.

In order to further understand the effects of applied back pressure and processing temperature on the chip consolidation, optical microscopy was used to investigate the pores of the recycled samples. As indicated by arrows in Fig. 4(a), a large number of pores were present in the specimen consolidated at $500{ }^{\circ} \mathrm{C}$ with a back pressure of $50 \mathrm{MPa}$; while no exposed pores were observed in the sample using a higher back pressure of $100 \mathrm{MPa}$ (Fig. $4(\mathrm{~b})$ ). In the sample pressed at $450{ }^{\circ} \mathrm{C}$ with a back pressure of $150 \mathrm{MPa}$, there were a large quantity of pores at the triple junction (as marked by ovals in Fig. 5(a)) and gaps between chip boundaries (as indicated by arrows in Fig. 5(a)). When the processing temperature increased to $500{ }^{\circ} \mathrm{C}$, the consolidated specimen appeared fairly dense and free of macro-pores, as shown in Fig. 5(b).

Combining with the relative density measurement, the optical microscopy observation demonstrates that higher imposed back pressure and processing temperature facilitates the pore closure and mechanical bonding, thereby improving densification. 


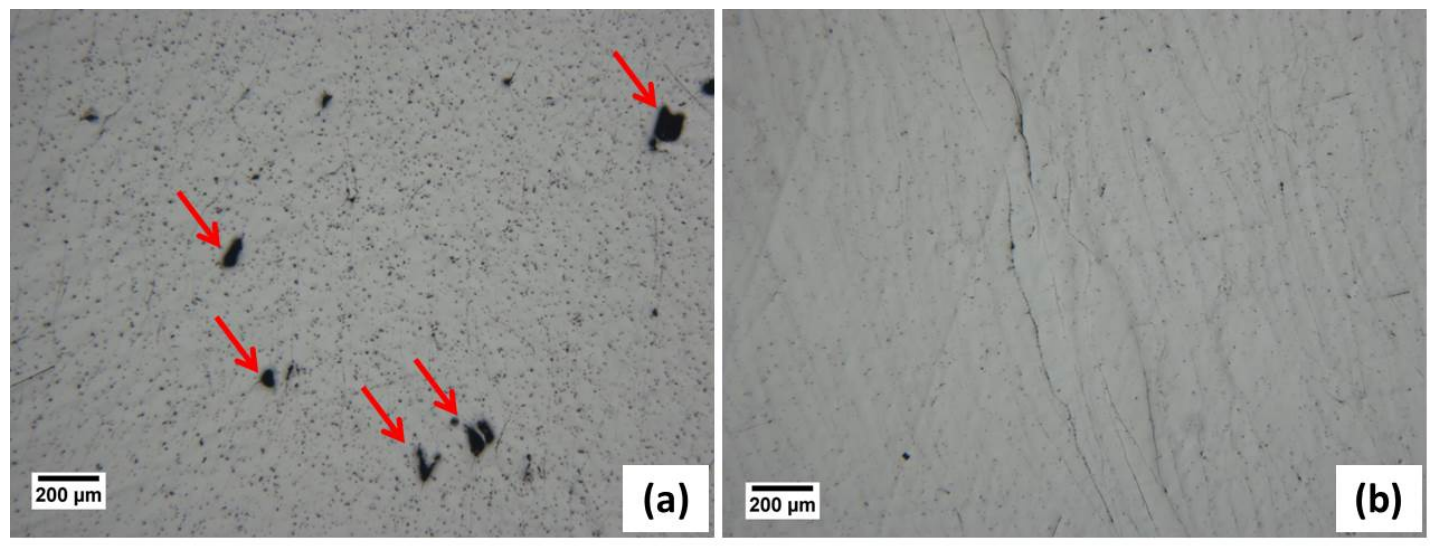

Fig. 4 Optical micrographs of Ti-15V-3Cr-3Al-3Sn chips consolidated after single pass at $500{ }^{\circ} \mathrm{C}$ with back pressures of (a) $50 \mathrm{MPa}$ and (b) $100 \mathrm{MPa}$.

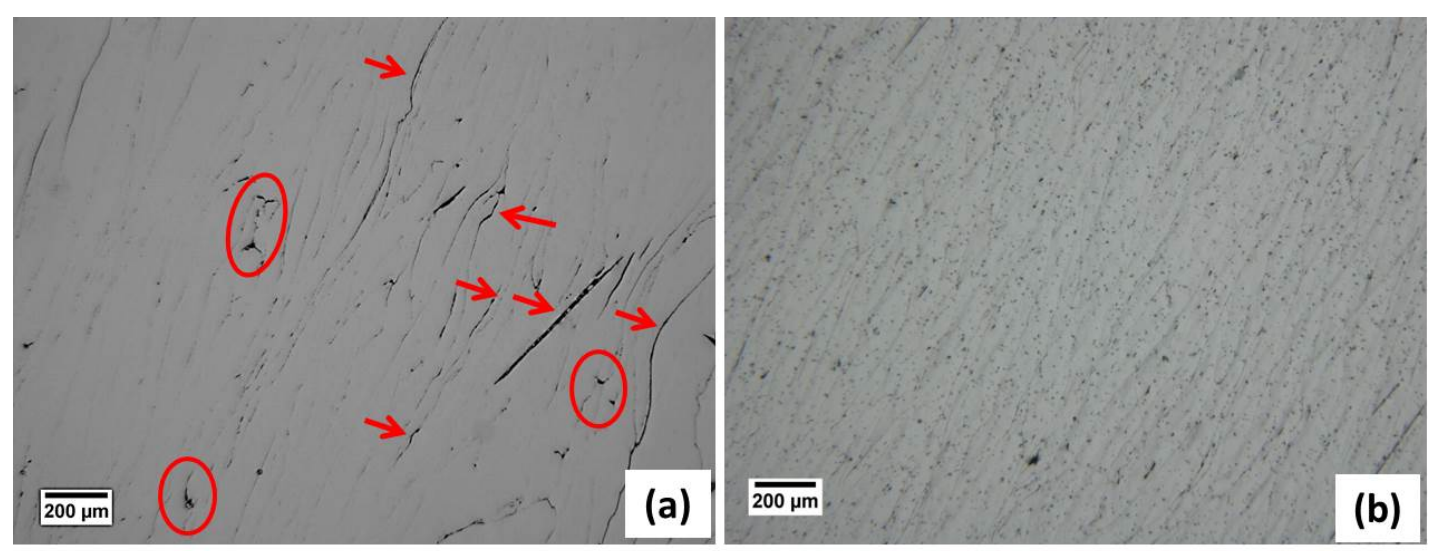

Fig. 5 Optical micrographs of Ti-15V-3Cr-3Al-3Sn chips consolidated after single pass with a back pressure of $150 \mathrm{MPa}$ at temperatures of (a) $450{ }^{\circ} \mathrm{C}$ and (b) $500^{\circ} \mathrm{C}$

All multiple-pass samples were processed at the temperature of $500{ }^{\circ} \mathrm{C}$. As illustrated in Fig. 6, under a fixed back pressure, the relative density increased with the number of passes. In this study, the highest relative density of $\sim 99.9 \%$ was achieved by the sample pressed for 8 passes with the aid of a back pressure of 100 MPa. As shown in Fig. 7, no obvious pores were found and the gap between chip boundaries was significantly reduced. 


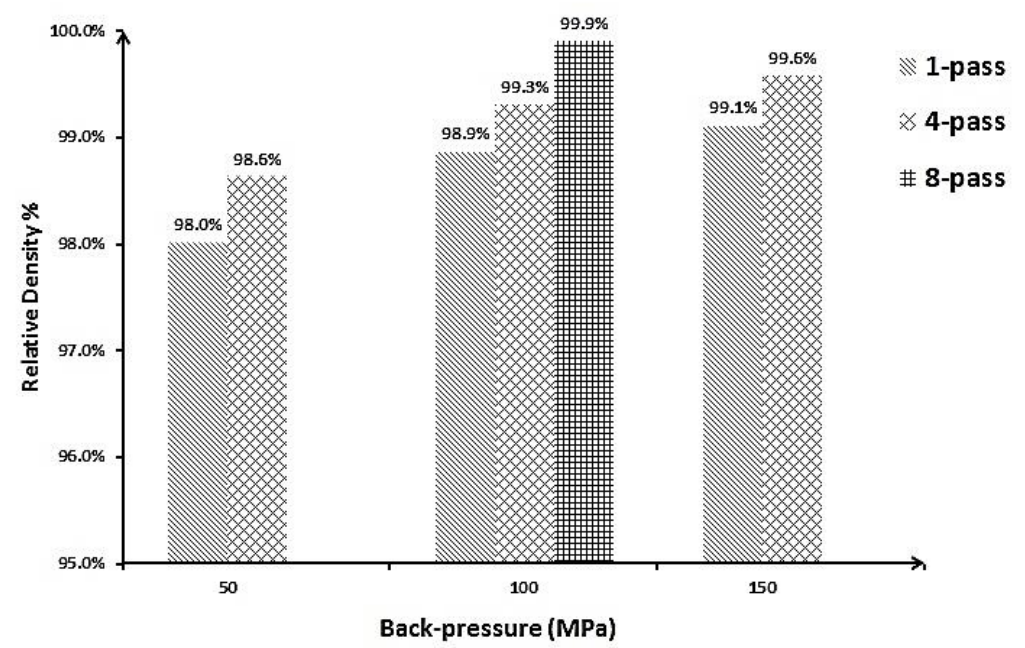

Fig.6 Relative densities of the recycled Ti-15V-3Cr-3Al-3Sn after multiple-pass ECAP at $500{ }^{\circ} \mathrm{C}$ using different back pressures.

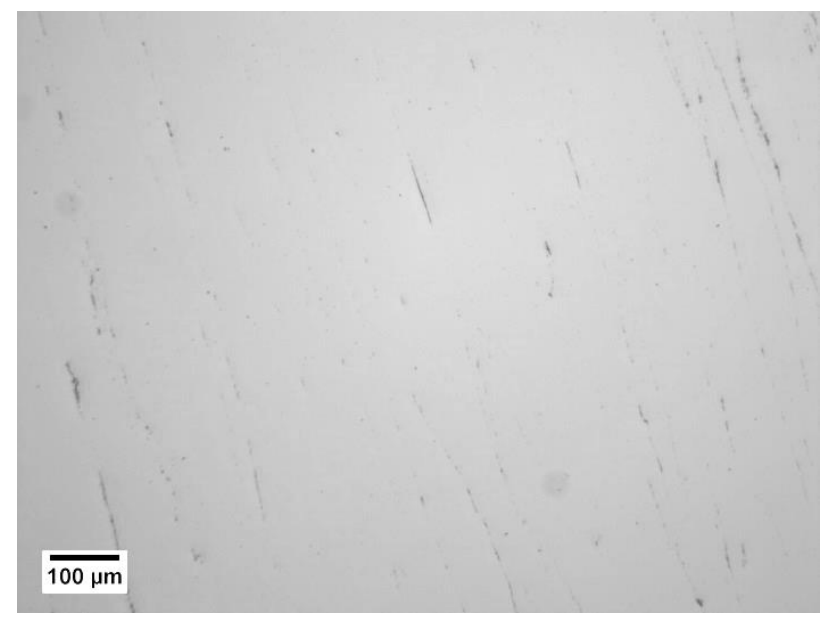

Fig. 7 Optical micrograph of recycled Ti-15V-3Cr-3Al-3Sn after 8 passes at $500{ }^{\circ} \mathrm{C}$ with a back pressure of $100 \mathrm{MPa}$.

\subsection{Microstructure characterization}

Fig. 8 shows the SEM backscattered electron micrograph of the specimen after 4 passes at $500{ }^{\circ} \mathrm{C}$ with a back pressure of $100 \mathrm{MPa}$. A dual phase microstructure was clearly observed: equiaxed $\alpha$ grains (dark contrast) and $\beta$ matrix (bright contrast). The size of $\alpha$ grains ranges from $150-200 \mathrm{~nm}$. 


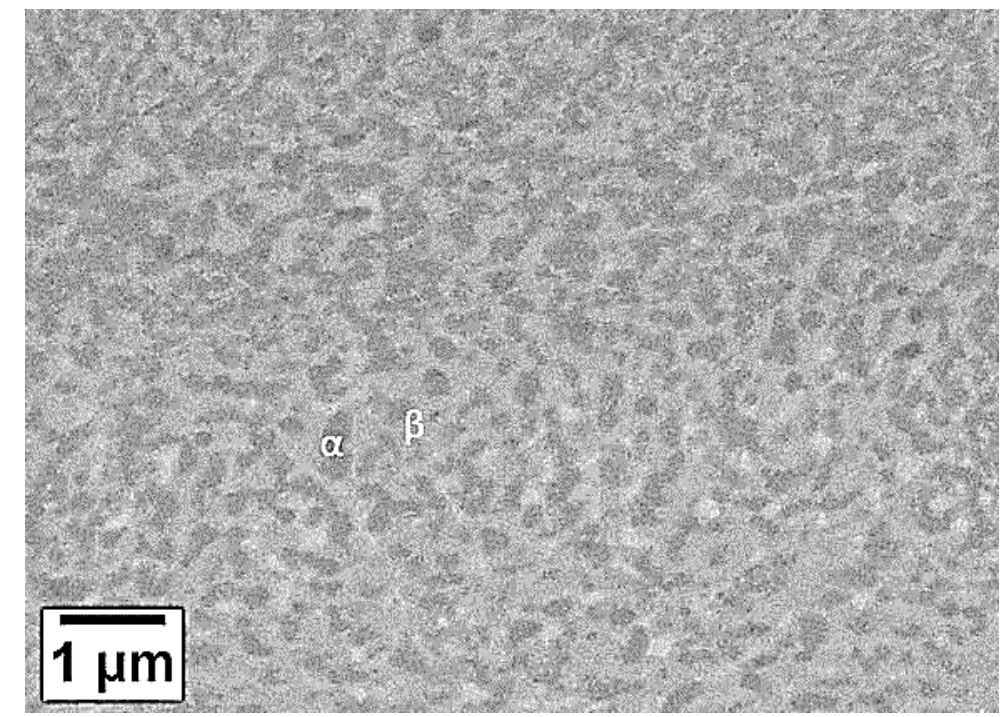

Fig. 8 A SEM backscatered image showing the dual microstructure of Ti-15V-3Cr-3Al-3Sn pressed at $500{ }^{\circ} \mathrm{C}$ with a back pressure of $100 \mathrm{MPa}$ for 4 passes.

Fig. 9 shows the TEM micrograph together with a representative selected area diffraction (SAD) pattern. The SAD ring pattern confirmed the formation of ultrafine $\alpha$ grains with high angle misorientation. Except a grains, due to the closed interplanar spacing, the $\beta$ reflections of $110_{\beta}$ and $200_{\beta}$ were revealed close to $10 \overline{1} 0_{\alpha}$ and $10 \overline{1} 2_{\alpha}$ reflections, respectively, as indicated by the arrows in Fig. 9(b).
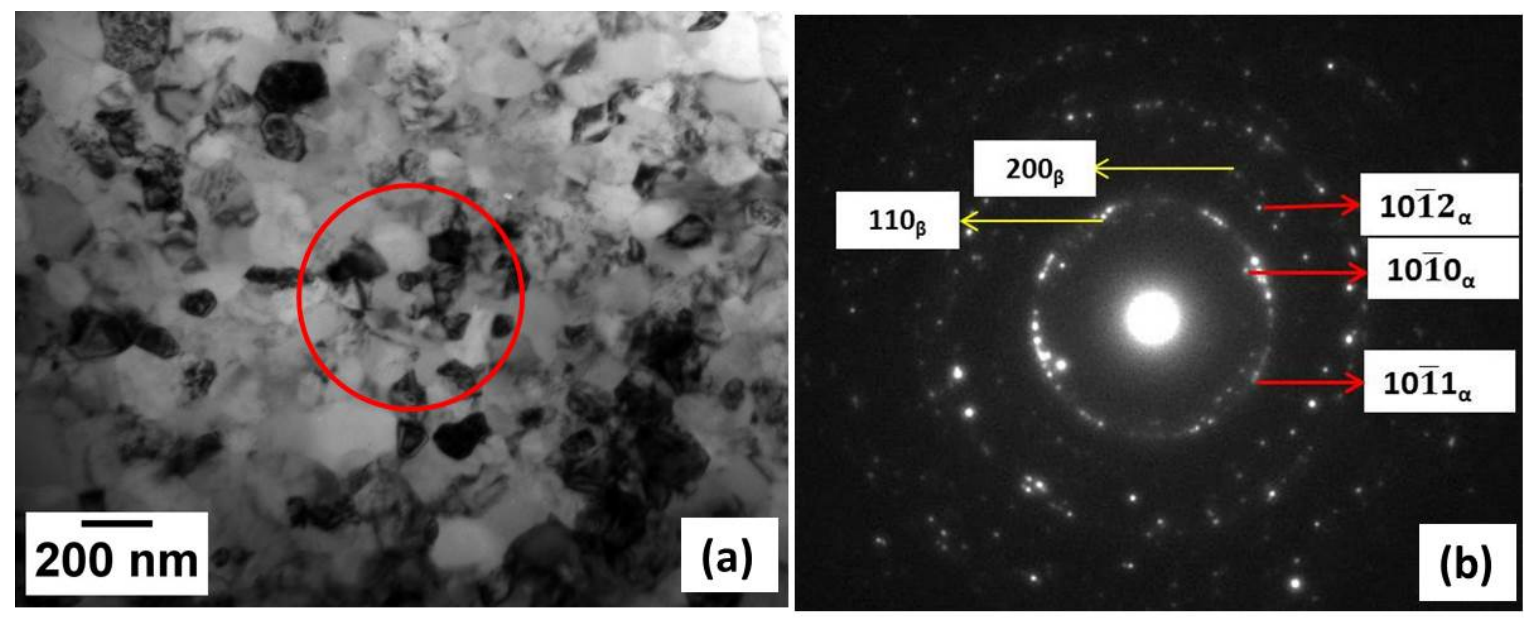

Fig. 9 (a) Bright field TEM micrograph and (b) the corresponding SAD pattern in the Ti-15V-3Cr-3Al$3 \mathrm{Sn}$ after 4 passes at $500^{\circ} \mathrm{C}$ with a back pressure of $100 \mathrm{MPa}$.

In order to further confirm the distribution of the equiaxed $\alpha$ grains in $\beta$ matrix, scanning TEM (STEM) analysis accompany with EDS mapping was carried out. A TEM bright field image (Fig. 10(a)) shows equiaxed ultrafine grains with clear boundaries. According to the contrast and the element distribution, several $\alpha$ and $\beta$ grains were indicated in Fig. 10(b) and (d). Distribution of elements, as shown in Fig. 
10(c) to (e), revealed that Al-rich and V/Cr-depleted a grains were homogeneously distributed in the $\beta$ matrix. It is noteworthy that the EDX map of Sn was identical with a stabilizer Al Map (Fig. 10(d)), although Sn is usually considered as a neutral element.
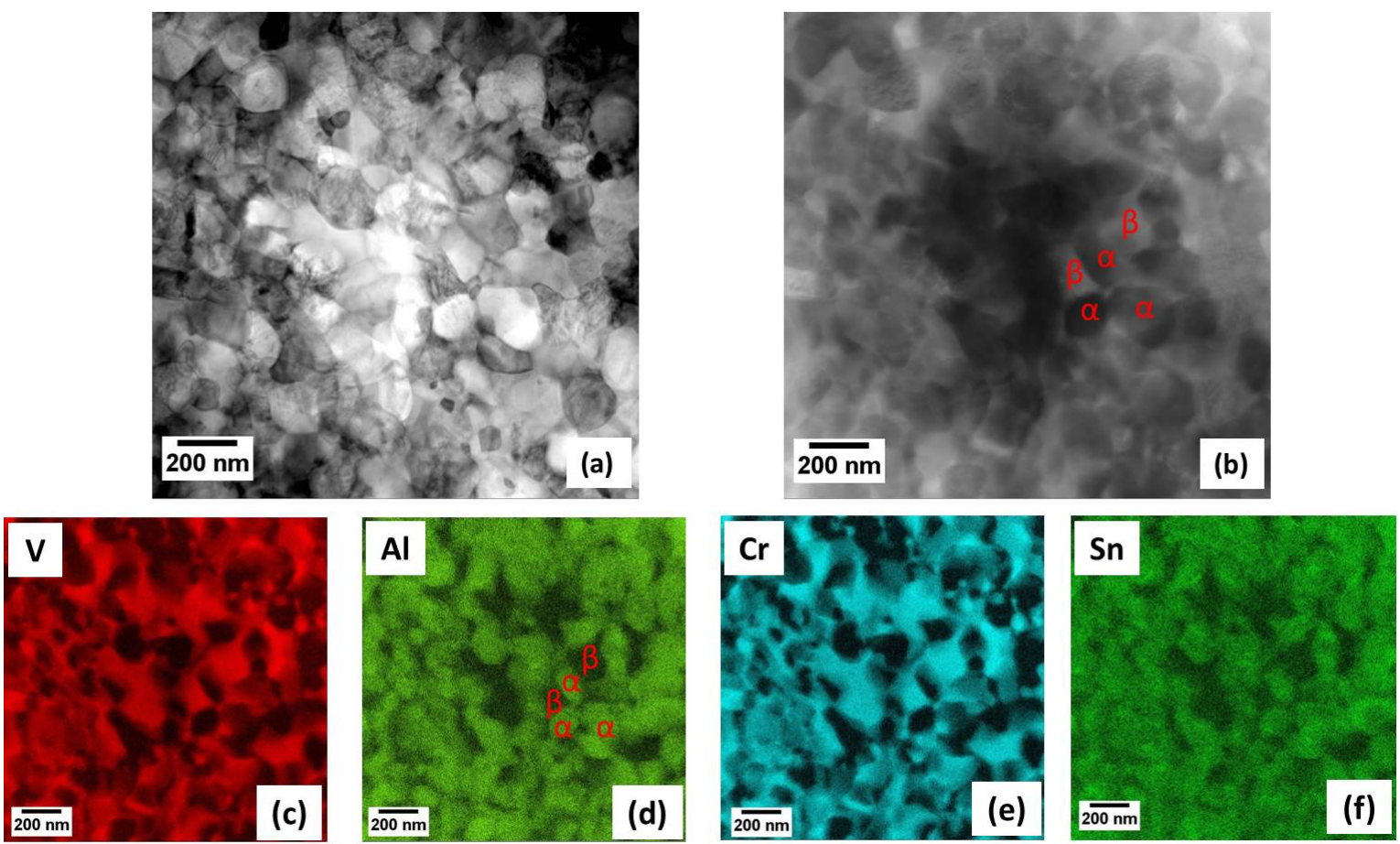

Fig.10 (S)TEM and EDS analyses of the recycled Ti-15V-3Cr-3Al-3Sn pressed at $500{ }^{\circ} \mathrm{C}$ with a back pressure of $100 \mathrm{MPa}$ after 4 passes: (a) conventional TEM bright field image, (b) a STEM image indicating the distribution of $\alpha$ and $\beta$ grains, (c) V, (d) Al, (e) Cr and (f) Sn elemental mappings.

Fig. 11 is a TEM many beam bright field micrograph showing entangled dislocations within an equiaxed grain. The high dislocation density could be attributed to the severe plastic shear deformation in the ECAP process.

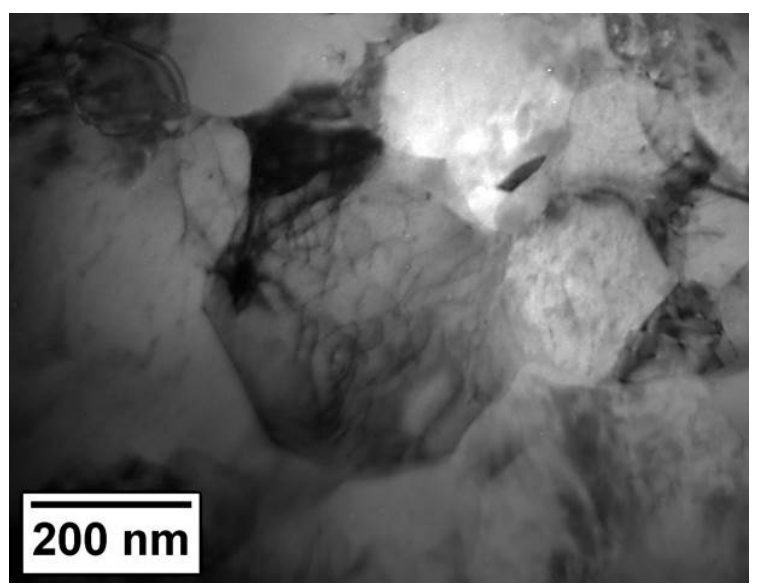

Fig. 11 Entangled dislocations within an equiaxed grain in the recycled Ti-15V-3Cr-3Al-3Sn. 
As revealed in Fig. 8 to Fig. 10, ultrafine and equiaxed a grains homogeneously formed in the $\beta$ matrix. This is different from the typical acicular a precipitates after aging at $350 \sim 700{ }^{\circ} \mathrm{C}$ for several hours, which heterogeneously forms at grain boundaries, sub-grain boundaries ${ }^{[27]}$ or interface between $\beta$ and secondary phases (e.g. $\omega$ phase) ${ }^{[28]}$. This difference can be explained based on the fact that the morphology of $\alpha$ phase precipitated from $\beta$ matrix is strongly correlated with the microstructure and the recovery process of the $\beta$ matrix. For undeformed $\beta-\mathrm{Ti}$, in order to minimize the activation energy for nucleation, the a precipitates prefer to nucleate at lattice defects in the way coherent with the $\beta$ matrix [29]. Moreover, the formation of $\alpha$ phase is restrained by the variant selections, and hence acicular shape. As explicated by Guo et al. ${ }^{[30]}$, the habit plane of a precipitates was $\{111\}_{\beta}$ and the orientation relationships between $\alpha$ precipitates and $\beta$ matrix were $\langle 11 \overline{2} 0\rangle_{\alpha}$ $\|<111\rangle_{\beta}$ and $\{0001\}_{\alpha} \|\{110\}_{\beta}$. These relationships were also confirmed by the experimental results obtained in hot-drawn Ti-15Nb-2Mo-2Zr-1Sn ${ }^{[31]}$.

In the present study, the material was subjected to intense shear deformation, thus a high density of dislocations and abundant subgrain/grain boundaries were created during ECAP. As known, the newly-formed grain boundaries during SPD possess non-equilibrium structures [32]. These non-equilibrium grain boundaries are characterized by an increased free energy density, increased width and high dislocation density, and hence preferential nucleation sites. In addition, a large number of shear bands were generated in the process of ECAP. It has been reported that there is a temperature increase within the shear bands of $\sim 40-85 \mathrm{~K}$ [33-36]. Therefore, the absolute temperature within the shear bands for the specimen demonstrated in Fig. 8 to Fig. 10 was supposed to be $\sim 813$ - $858 \mathrm{~K}$. This temperature was high enough for dynamic recovery (recovery leading the formation of subgrain and cell structure of dislocations, do you know the temperature for alpha to precipitate from the phase diagram?)) of $\mathrm{Ti}-15 \mathrm{~V}-3 \mathrm{Cr}-3 \mathrm{Al}-3 \mathrm{Sn}$, leading to simultaneous dynamic a precipitation. Furthermore, the severe deformation induced non-equilibrium grain boundaries ${ }^{[32 ; 37 ; 38]}$ and vacancies ${ }^{[39 ; 40]}$ play a role as fast diffusion paths for atom transport. This increases the atom diffusivity by several orders of magnitude ${ }^{[41 ; 42]}$, thus facilitates a nucleus to grow into equiaxed grains. Moreover, the high concentration of vacancies caused by ECAP weakens the preferred variant selection of a precipitates ${ }^{[43]}$, thereby a more random rather than 
the Burgers orientation relationship was attained between the $\alpha$ precipitation and $\beta$ matrix. Similar ultrafine-duplex $(\alpha+\beta)$ structures were also observed within the shear bands of severely deformed Ti-20Mo ${ }^{[41 ; 43]}$. Nevertheless, it should be noted that different from the previous studies, the raw material in the current experiment was machining chips, rather than bulk $\beta$-Ti after solution treatment. According to our previous study ${ }^{[26]}$, abundant nanocrystalline $\beta$ grains formed within the primary and secondary shear zones during the machining process, i.e. plentiful heavily deformed structures had formed prior to ECAP. During heating to the ECAP temperature, recovery of the heavily deformed structures was supposed to proceed and form subgrain structures due to a large amount of stored energy. Meanwhile, the $\alpha$ precipitates nucleated at the sub-grain boundary nodes and grew into equiaxed grains via fast diffusion paths. Thereby, in the present study, the ultrafine-duplex microstructure formed by both dynamic and static precipitation.

It is noteworthy that some $\alpha$ precipitates obeying the Burgers orientation relationship with the $\beta$ matrix were also found in some area. As illustrated in Fig. 12(b), it is found that the $\alpha$ grains precipitated adjacent to the nano-sized $\beta$ grain (as indicated by the red circle in Fig. 12(a)) coincided with the variant selections. The corresponding SAD pattern shows the zone axis of $[\overline{1} 10]_{\beta}$. An identical SAD pattern has been also reported in the reference ${ }^{[30]}$, and the calibrated pattern is illustrated in Fig. 12(c). It can be found that the diffraction spots of variants $(100)_{2 \alpha}$ and $(100)_{12 \alpha}$ spread to barlike pattern along the $[111]_{\beta}$ and $[11 \overline{1}]_{\beta}$ directions, respectively. Based on the investigation conducted by Guo et al. [30], the $\alpha$ variant 2 and $\alpha$ variant 12 lie on the planes of $(111)_{\beta}$ and $(11 \overline{1})_{\beta}$, respectively. 


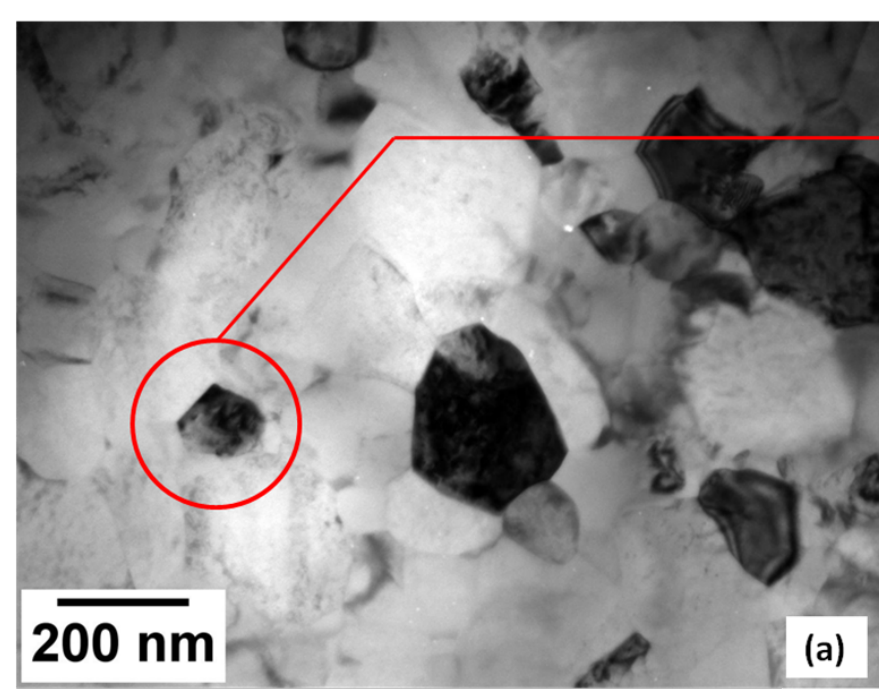

(a)
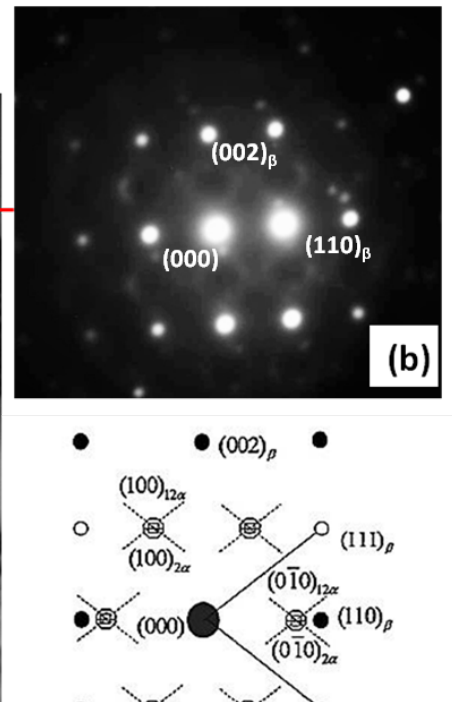

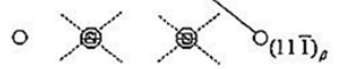

(c)

- $\beta$ phase $\triangle a$ variant $2 \ominus \alpha$ variant 12

$\circ$ Extinction spots of $\beta$ phase

Fig. 12 (a) TEM micrograph of Ti-15V-3Cr-3Al-3Sn consolidated by ECAP at $500{ }^{\circ} \mathrm{C}$ for 4 passes, (b) $S A D$ pattern taken from the $\beta$ grain in (a), (c) calibrated $S A D$ pattern of (b) ${ }^{[30]}$.

Fig. 13(a) is a TEM micrograph showing an interface between two chips. It is obvious that although the chips were mechanically bonded by severe shear deformation, there were still some nano-sized pores remained along the interface, as indicated by arrows. The corresponding ring-shaped SAD pattern taken from the bonding area, as shown in Fig. 13(b), revealed the presences of nanocrystalline a phase and very weak $\{110\}_{\beta}$ reflection, which was very close to $\{10 \overline{1} 0\}_{\alpha}$. A TEM image at higher magnification (Fig. 13(c)) shows that the bonding zone was $\sim 250 \mathrm{~nm}$ in width. The grains in the vicinity of the bonding zone were only $\sim 30 \mathrm{~nm}$ or even smaller in diameter, while the microstructure became coarser as the distance to the bonding zone increased. This affected zone was correlated to the severe shear deformation occurred during the mechanical bonding. 

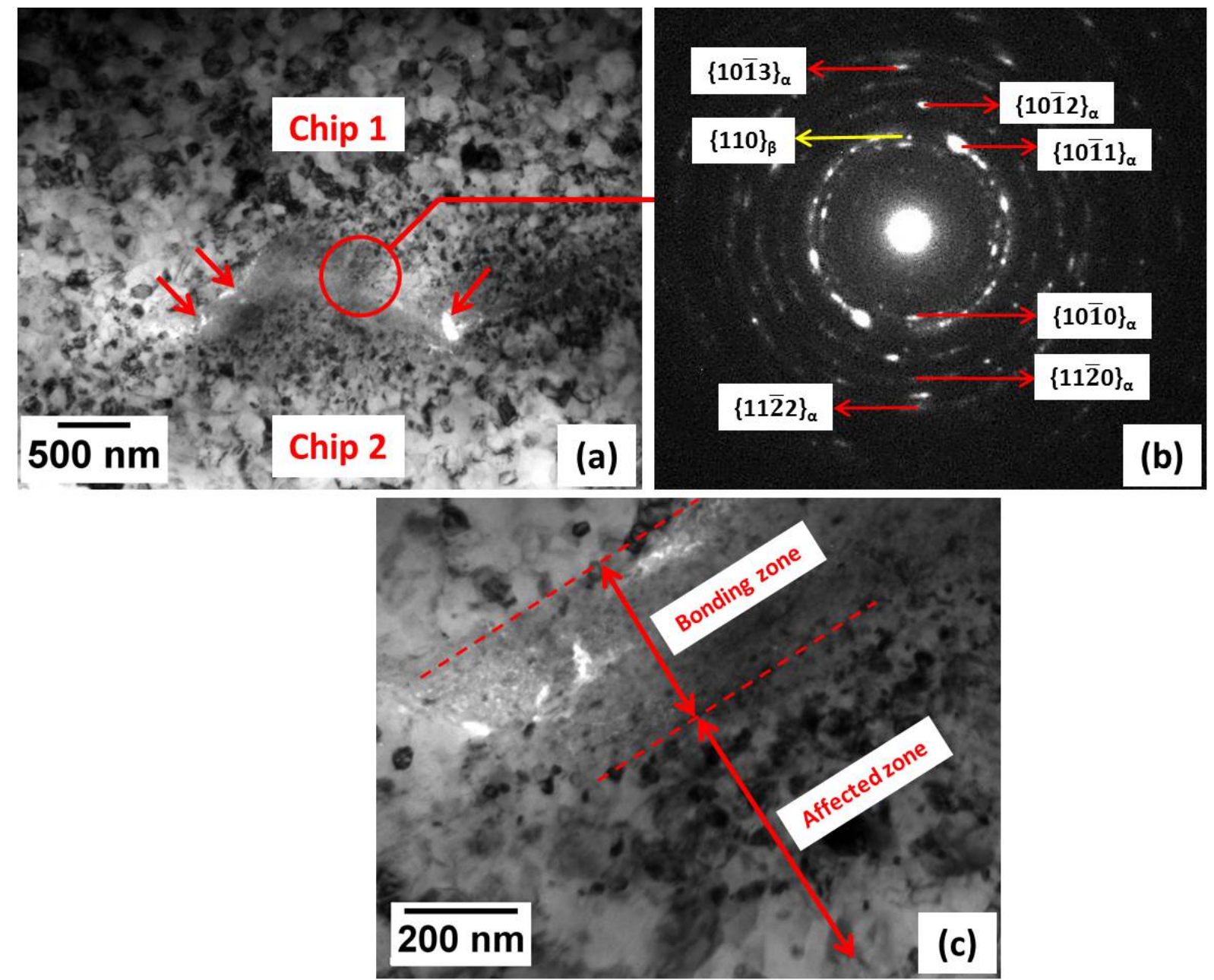

Fig.13 (a) TEM image showing the chip/chip interface, (b) the SAD pattern taken from the interface and (c) higher magnification TEM image showing the bonding zone and the affected zone.

\subsection{Microhardness Measurement}

The average hardness and corresponding standard derivations of the single ECAPed samples are illustrated in Fig. 14. In comparison with the as-received bulk material, the microhardness has a distinct improvement of $\sim 83.7 \%$ after only singlepass ECAP. Combined with the TEM examination, the enhancement can be attributed to the formation of ultrafine grains and the increase in dislocation density induced by imposed heavy strain. Another possible reason is the age hardening simultaneously occurred during the ECAP process. Large amount of previous researches have been reported the aging effect on the mechanical properties of Ti$15 \mathrm{~V}-3 \mathrm{Cr}-3 \mathrm{Al}-3 \mathrm{Sn}$ alloy $[27 ; 44-47]$. According to the experiments carried out in the previous study ${ }^{[44]}$, the peak hardness $(\sim 435 \mathrm{Hv})$ was achieved at the aging temperature of $\sim 426{ }^{\circ} \mathrm{C}$, and the hardness decreased to $\sim 396 \mathrm{Hv}$ when Ti-15V-3Cr- 
3Al-3Sn was aged at $\sim 482{ }^{\circ} \mathrm{C}$. They demonstrated that too low aging-temperature had little influence on the mechanical properties, while an excessive increase above the optimum aging-temperature would lead to over-aging and result in hardness drop because of the a precipitation coarsening. Overall, the variation in microhardness of recycled Ti-15V-3Cr-3Al-3Sn in the current study was generally consistent with the previous experimental results ${ }^{[44 ; 45]}$.

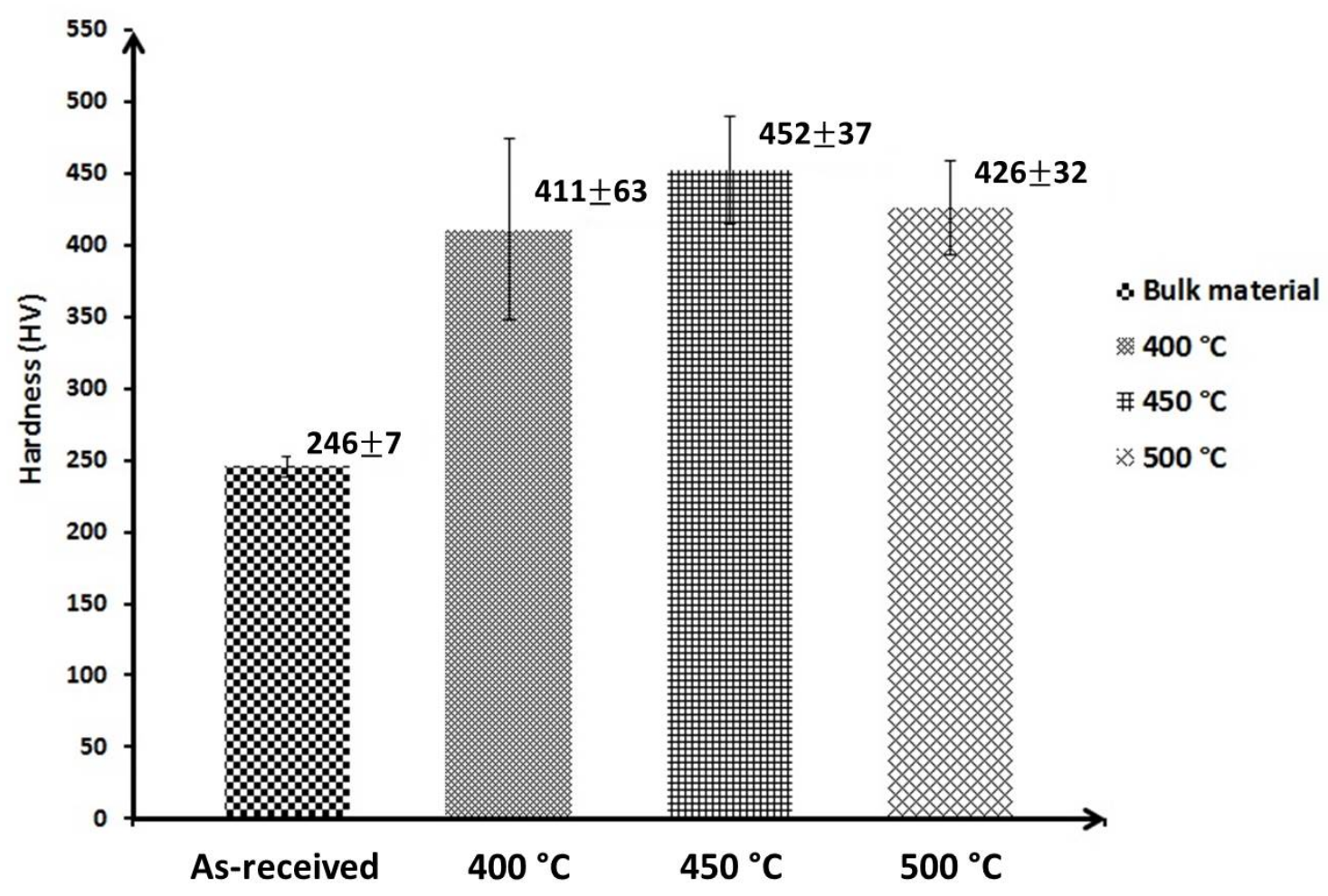

Fig. 14 The average hardness for as-received bulk Ti-15V-3Cr-3Al-3Sn and recycled samples

As shown in the colour-coded contour maps (Fig. 15(a) to (c)), there was a profound heterogeneity in microhardness for the single ECAPed samples. Combining with the optical micrographs (Fig. 4 and Fig. 5), the heterogeneity is due to the remained pores and chip boundaries. The extent of the heterogeneity is quantitatively depicted by the distribution curves in Fig. 15(d). It is obvious that the hardness variation in each sample is narrowed with the increasing process temperature. This can be explained by the fact that the alloy chips consolidated at higher temperature possessed better deformability, thus more pore elimination and improved homogeneity. 


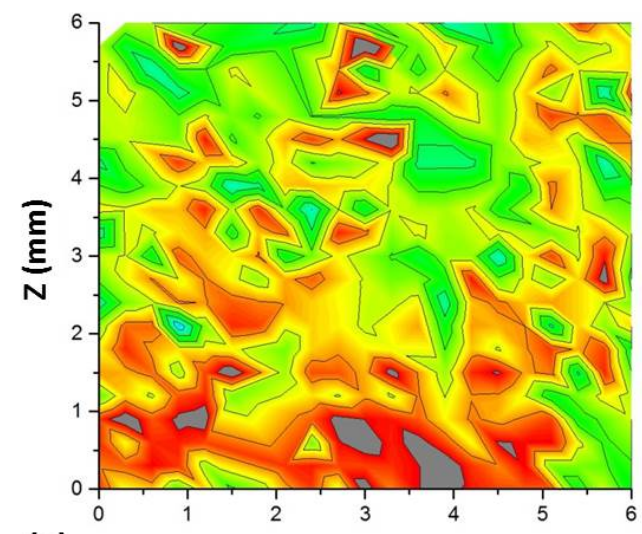

(a)
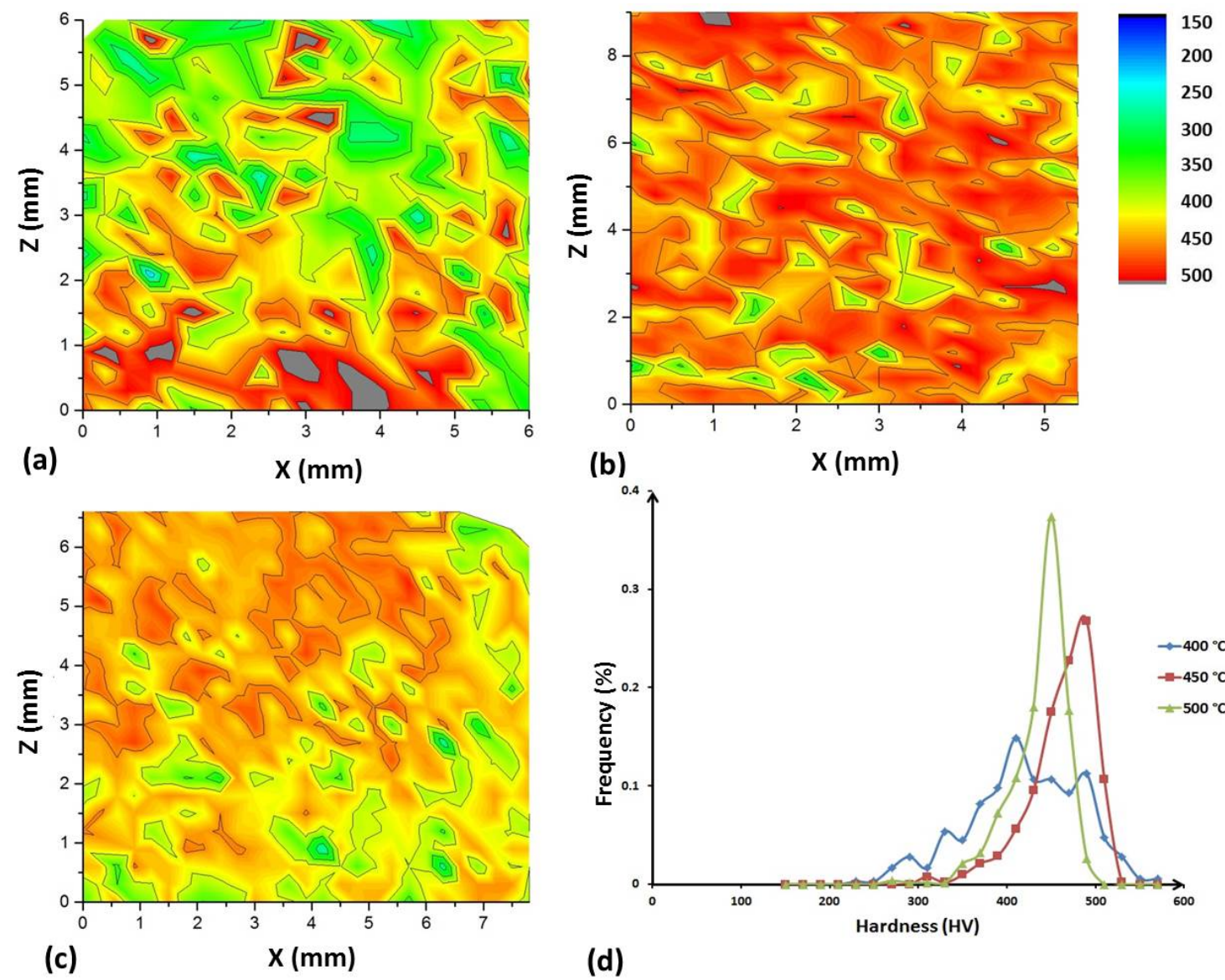

(b)

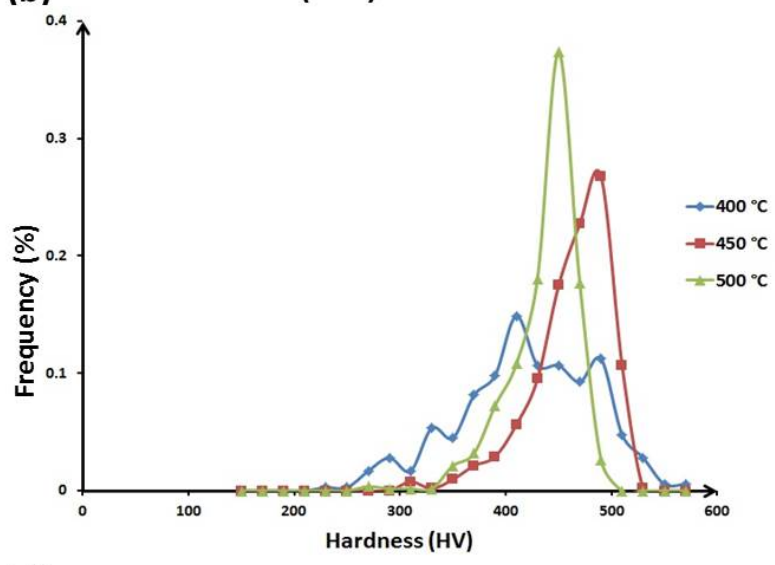

(d)

Fig. 15 Colour-coded contour maps showing the microhardness distribution on the specimen recycled by single pass ECAP with a back pressure of $50 \mathrm{MPa}$ at (a) $400{ }^{\circ} \mathrm{C}$, (b) $450^{\circ} \mathrm{C}$ and (c) $500{ }^{\circ} \mathrm{C}$; (d) the corresponding distribution curves.

Fig. 16(a) to (c) present the colour-coded contour maps of the multi-ECAPed samples. From Fig. 16(a) and (b), it can be clearly seen that there were narrow regions of lower hardness along the bottom surface after 1 and 4 passes, while as shown in Fig. 16(c), the low-hardness band had been almost removed after 8 passes. This is because that every edge had experienced equivalent and severe plastic strain after 8 passes following route $\mathrm{B}_{\mathrm{c}}$. In addition, it is observed that besides the bottom area, the hardness at the central region slightly decreased with the number of passes and the average value over the flow plane almost kept steady. It is because the dislocation density saturates after multiple passes and many of the sub-grain boundaries evolve into high-angle grain boundaries ${ }^{[48]}$. The distribution curves (Fig. 16 (d)) confirmed that a higher homogeneity was achieved with the pass number from 1 to 8 . The corresponding average hardness remained essentially unchanged: $403 \mathrm{HV}, 401 \mathrm{HV}$ and $407 \mathrm{HV}$ for 1, 4 and 8 passes, respectively. 


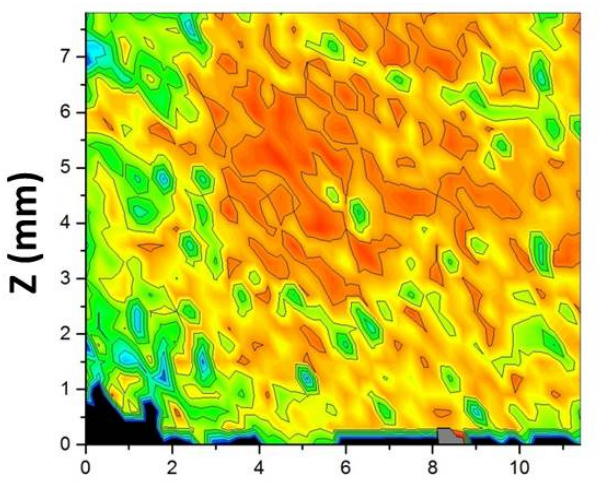

(a)

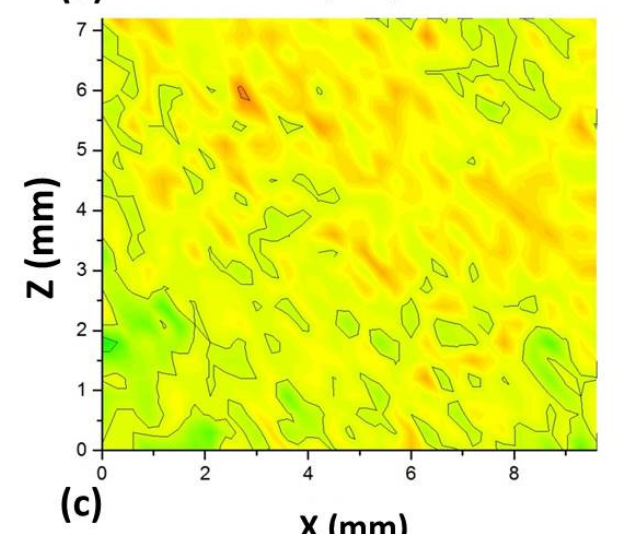

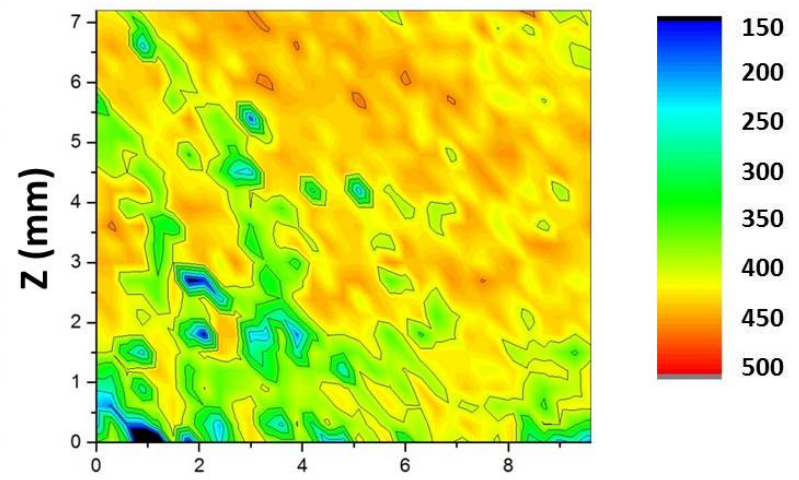

(b)

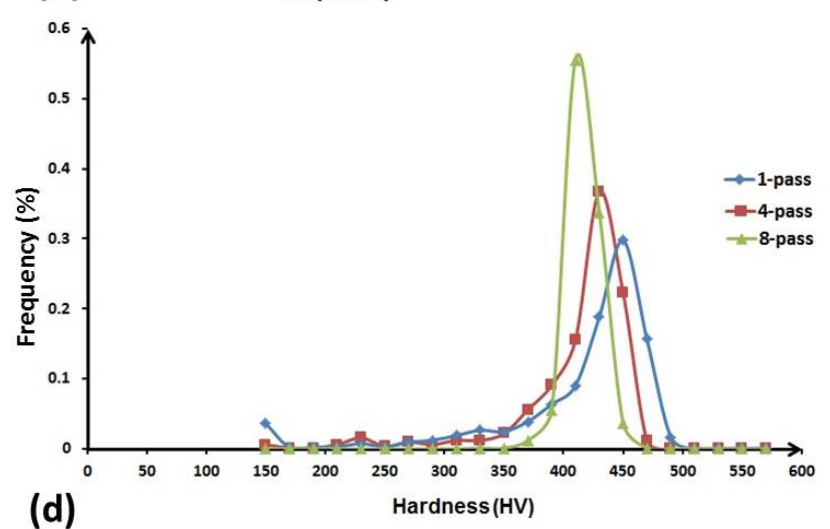

(d)

Fig. 16 Colour-coded contour maps showing the microhardness distribution on Ti-15V-3Cr-3Al-3Sn recycled at $500{ }^{\circ} \mathrm{C}$ with a back pressure of $100 \mathrm{MPa}$ after (a) 1, (b) 4, (c) 8 passes and (d) the corresponding distribution curves.

\section{Conclusions}

In this work, we have successfully employed back pressure assisted equal channel angular pressing (BP-ECAP) technique to recycle Ti-15V-3Cr-3Al-3Sn alloy from machining chips at moderate temperatures and systematically investigate the relative density, microstructure evolution and hardness of the recycled products. Based on the experimental observations and analyses, the following conclusions can be drawn:

(1) The relative density measurements show that the increases in applied back pressures, temperatures and number of passes facilitate Ti-15V-3Cr-3Al-3Sn machining chip consolidation. The near fully dense specimen was obtained after 8 passes at $500{ }^{\circ} \mathrm{C}$ with a back pressure of $100 \mathrm{MPa}$.

(2) SEM and (S)TEM examinations demonstrate the presence of ultrafine equiaxed $\alpha$ precipitates within the $\beta$ matrix in the recycled specimens. It is suggested that high dislocation density and abundant grain/sub-grain boundaries introduced by severe shear deformation during ECAP offer substantial nucleation sites for $\alpha$ 
precipitates; furthermore, large amount of vacancies and non-equilibrium grain boundaries facilitate atom diffusion and accelerate precipitate growth. Random orientation relationship between $\alpha$ precipitates and the $\beta$ matrix exists in most regions, which may be due to the high concentration of vacancies caused by ECAP weakening the preferred variant selection of $\alpha$ precipitates.

(3) BP-ECAP at moderate temperatures gives a significant enhancement of $\sim 83.7 \%$ in microhardness for recycled Ti-15V-3Cr-3Al-3Sn. The corresponding reasons are twofold: Firstly, the high shear strain introduced during ECAP leads to grain refinement and the increase in dislocation density; secondly, the formation of ultrafine $\alpha$ precipitates in the $\beta$ matrix as a result of age hardening during the ECAP process. It was found that the average hardness value is dependent on the processing temperature. The specimen pressed at $450{ }^{\circ} \mathrm{C}$ had the peak hardness value. The increase in number of passes has no effect on the hardness enhancement but improve the homogeneity.

\section{Acknowledgements}

The authors are greatly indebted to $\mathrm{Dr}$ Riaz Muhammad and Dr Anish Roy from School of Mechanical and Manufacturing Engineering in Loughborough University for providing machining chips. The authors also acknowledge $\mathrm{Dr}$ Zhaoxia Zhou and $\mathrm{Mr}$ Scott Doak in Loughborough Materials Characterization Centre (LMCC) for their help in TEM work.

\section{References}

[1] Deshpande A M P, Vanitha C, Singh A. K., . Microstructural Characterization of Metastable Beta Titanium Alloys in Hot Rolled and Solution Treated condition[J]. Materials Today: Proceedings, 2018, 5(2): 3657-3663.

[2] Chen W C S, Kou W, Zhang J, Wang Y, Zha Y, Pan Y, Hu Q, Sun Q, Sun J, . Origin of the ductile-to-brittle transition of metastable $\beta$-titanium alloys: Selfhardening of $\omega$-precipitates[J]. Acta Mater., 2019, 170: 187-204.

[3] Cox A H S, Villain-Chastre J.-P, Turner S, Jackson M, . The effect of machining and induced surface deformation on the fatigue performance of a high strength metastable $\beta$ titanium alloy[J]. Internation Journal of Fatigue, 2019, 124: 26-33.

[4] Leyens C, Peters M. Titanium and Titanium Alloys: Fundamentals and Applications[M]. 2003: 401.

[5] Boyer R R, Briggs R D. The use of $\beta$ titanium alloys in the aerospace industry[J]. Journal of Materials Engineering \& Performance, 2005, 14(6): 681-685. 
[6] Murr L E, Quinones S A, Gaytan S M, et al. Microstructure and mechanical behavior of Ti-6Al-4V produced by rapid-layer manufacturing, for biomedical applications[J]. Journal of the Mechanical Behavior of Biomedical Materials, 2009, 2(1): 20-32.

[7] Modrzyński A, Greześkowiak K, Namyślak R. Recycling of titanium alloys in plasma furnace[J]. Czechoslovak Journal of Physics, 2004, 54(3): C1016-C1021.

[8] Burkhard R, Hoffelner W, Eschenbach R C. Recycling of metals from waste with thermal plasma[J]. Resources Conservation \& Recycling, 1994, 10(s 1-2): 11-16.

[9] Valiev R Z, Islamgaliev R K, Alexandrov I V. Bulk nanostructured materials from severe plastic deformation[J]. Progress in Materials Science, 1999, 45(2): 103-189.

[10] Valiev R Z, Estrin Y, Horita Z, et al. Producing bulk ultrafine-grained materials by severe plastic deformation[J]. Journal of Plasticity Engineering, 2010, 58(4): 33-39.

[11] Valiev R Z, Langdon T G. Principles of equal-channel angular pressing as a processing tool for grain refinement[J]. Progress in Materials Science, 2006, 51(7): 881-981.

[12] Zhilyaev A P, Langdon T G. Using high-pressure torsion for metal processing: Fundamentals and applications[J]. Progress in Materials Science, 2008, 53(6): 893979.

[13] Yang G, Li Z, Yuan Y, et al. Microstructure, mechanical properties and electrical conductivity of $\mathrm{Cu}-0.3 \mathrm{Mg}-0.05 \mathrm{Ce}$ alloy processed by equal channel angular pressing and subsequent annealing[J]. Journal of Alloys \& Compounds, 2015, 640(2): 347-354.

[14] Zhang J, Kang Z, Zhou L. Microstructure evolution and mechanical properties of Mg-Gd-Nd-Zn-Zr alloy processed by equal channel angular pressing[J]. Materials Science \& Engineering A, 2015, 647: 184-190.

[15] Darling K A, Tschopp M A, Guduru R K, et al. Microstructure and mechanical properties of bulk nanostructured $\mathrm{Cu}-\mathrm{Ta}$ alloys consolidated by equal channel angular extrusion[J]. Acta Materialia, 2014, 76(5): 168-185.

[16] Nejadseyfi O, Shokuhfar A, Dabiri A, et al. Combining equal-channel angular pressing and heat treatment to obtain enhanced corrosion resistance in 6061 aluminum alloy[J]. Journal of Alloys \& Compounds, 2015, 648: 912-918.

[17] Haase M, Khalifa N B, Tekkaya A E, et al. Improving mechanical properties of chip-based aluminum extrudates by integrated extrusion and equal channel angular pressing (iECAP)[J]. Materials Science \& Engineering A, 2012, 539(2): 194-204.

[18] Hyodo, Alexandrebolfarini, Claudemiroishikawa, et al. Chemistry and tensile properties of a recycled AA7050 via spray forming and ECAP/E[J]. Materials Research, 2012, 15(5): 739-748.

[19] Tao Y, Zheng M Y, Xiao-Shi H U, et al. Recycling of AZ91 Mg alloy through consolidation of machined chips by extrusion and ECAP[J]. 中国有色金属学报(英文 版), 2010, 20(s2): s604-s607.

[20] Chino Y, Hoshika T, Lee J S, et al. Mechanical properties of AZ31 Mg alloy recycled by severe deformation[J]. Journal of Materials Research, 2006, 21(3): 754760.

[21] Luo P, Mcdonald D T, Zhu S M, et al. Analysis of microstructure and strengthening in pure titanium recycled from machining chips by equal channel angular pressing using electron backscatter diffraction[J]. Materials Science \& Engineering A, 2012, 538(3): 252-258.

[22] Luo P, Mcdonald D T, Xu W, et al. A modified Hall-Petch relationship in ultrafine-grained titanium recycled from chips by equal channel angular pressing[J]. Scripta Materialia, 2012, 66(10): 785-788. 
[23] Shi $Q$, Tse $Y Y$, Higginson $R$ L. Effects of processing parameters on relative density, microhardness and microstructure of recycled Ti-6Al-4V from machining chips produced by equal channel angular pressing[J]. Materials Science \& Engineering A, 2016, 651: 248-258.

[24] Mcdonald D T, Luo P, Palanisamy S, et al. Ti-6Al-4V Recycled from Machining Chips by Equal Channel Angular Pressing[J]. Key Engineering Materials, 2012, 520: 295-300.

[25] Mcdonald D T, Lui E W, Palanisamy S, et al. Achieving Superior Strength and Ductility in Ti-6Al-4V Recycled from Machining Chips by Equal Channel Angular Pressing[J]. Metallurgical \& Materials Transactions A, 2014, 45(9): 4089-4102.

[26] Shi Q, Tse $Y Y$, Muhammad R, et al. Effect of Machining on Shear-Zone Microstructure in Ti-15V-3Cr-3Al-3Sn: Conventional and Ultrasonically Assisted Turning[J]. Journal of Materials Engineering \& Performance, 2016, 25(9): 3766-3773. [27] Makino T, Chikaizumi R, Nagaoka T, et al. Microstructure development in a thermomechanically processed $\mathrm{Ti} 15 \mathrm{~V} 3 \mathrm{Cr} 3 \mathrm{Sn} 3 \mathrm{Al}$ alloy[J]. Materials Science \& Engineering A, 1996, 213(s 1-2): 51-60.

[28] Nag S, Banerjee R, Srinivasan R, et al. $\omega$-Assisted nucleation and growth of $\alpha$ precipitates in the Ti-5Al-5Mo-5V-3Cr-0.5Fe $\beta$ titanium alloy[J]. Acta Materialia, 2009, 57(7): 2136-2147.

[29] Furuhara T, Maki T. Variant selection in heterogeneous nucleation on defects in diffusional phase transformation and precipitation[J]. Materials Science \& Engineering A, 2001, 312(1): 145-154.

[30] Guo Q, Wang Q, Han X L, et al. Crystalline characteristics of alpha precipitates in Ti-15V-3Sn-3Al-3Cr alloy[J]. Micron, 2010, 41(6): 565-570.

[31] Li T, Kent D, Sha G, et al. Precipitation of the a-phase in an ultrafine grained beta-titanium alloy processed by severe plastic deformation[J]. Materials Science \& Engineering A, 2014, 605: 144-150.

[32] Sauvage X, Wilde G, Divinski S V, et al. Grain boundaries in ultrafine grained materials processed by severe plastic deformation and related phenomena $\hat{\tau}[\mathrm{J}]$. Materials Science \& Engineering A, 2012, 540(4): 1-12.

[33] Yamaguchi D, Horita Z, Nemoto M, et al. Significance of adiabatic heating in equal-channel angular pressing[J]. Scripta Materialia, 1999, 41(8): 791-796.

[34] Nishida $Y$, Ando T, Nagase $M$, et al. Billet temperature rise during equal-channel angular pressing[J]. Scripta Materialia, 2002, 46(3): 211-216.

[35] Pei Q X, Hu B H, Lu C, et al. A finite element study of the temperature rise during equal channel angular pressing[J]. Scripta Materialia, 2003, 49(4): 303-308.

[36] Xu Y, Zhang J, Bai Y, et al. Shear Localization in Dynamic Deformation: Microstructural Evolution[J]. Metallurgical \& Materials Transactions A, 2008, 39(4): 811.

[37] Divinski S V, Reglitz G, Rösner H, et al. Ultra-fast diffusion channels in pure Ni severely deformed by equal-channel angular pressing[J]. Acta Materialia, 2011, 59(5): 1974-1985.

[38] Divinski S V, Ribbe J, Baither D, et al. Nano- and micro-scale free volume in ultrafine grained $\mathrm{Cu}-1 \mathrm{wt} \% \mathrm{~Pb}$ alloy deformed by equal channel angular pressing[J]. Acta Materialia, 2009, 57(19): 5706-5717.

[39] Setman D, Schafler E, Korznikova E, et al. The presence and nature of vacancy type defects in nanometals detained by severe plastic deformation[J]. Materials Science \& Engineering A, 2008, 493(1-2): 116-122. 
[40] Zehetbauer M, Steiner G, Schafler E, et al. Deformation Induced Vacancies with Severe Plastic Deformation: Measurements and Modelling[J]. Materials Science Forum, 2006, 503(1): 57-64.

[41] Xu W, Edwards D P, Wu X, et al. Promoting nano/ultrafine-duplex structure via accelerated $\alpha$ precipitation in a $\beta$-type titanium alloy severely deformed by highpressure torsion[J]. Scripta Materialia, 2013, 68(1): 67-70.

[42] Sauvage X, Wetscher F, Pareige P. Mechanical alloying of $\mathrm{Cu}$ and Fe induced by severe plastic deformation of a Cu-Fe composite[J]. Acta Materialia, 2005, 53(7): 2127-2135.

[43] Xu W, Wu X, Stoica M, et al. On the formation of an ultrafine-duplex structure facilitated by severe shear deformation in a Ti-20Mo $\beta$-type titanium alloy[J]. Acta Materialia, 2012, 60(13-14): 5067-5078.

[44] Hsu H H, Wu Y C, Tsay L W. Notch brittleness of Ti-15V-3Cr-3Sn-3Al alloys[J]. Materials Science \& Engineering A, 2012, 545: 20-25.

[45] Santhosh R, Geetha M, Saxena V K, et al. Studies on single and duplex aging of metastable beta titanium alloy $\mathrm{Ti}-15 \mathrm{~V}-3 \mathrm{Cr}-3 \mathrm{Al}-3 \mathrm{Sn}[\mathrm{J}]$. Journal of Alloys \& Compounds, 2014, 605(9): 222-229.

[46] Ma J, Wang Q. Aging characterization and application of Ti-15-3 alloy[J]. Materials Science \& Engineering A, 1998, 243(1): 150-154.

[47] Lin H C, Wang L M. Improved mechanical properties of Ti-15V-3Cr-3Sn-3Al alloy by electron beam welding process plus heat treatments and its microstructure evolution[J]. Materials Chemistry \& Physics, 2011, 126(3): 891-897.

[48] Vaclav Sklenicka J D, Milan Svoboda, Petr Kral, Kvapilova M. Equal-Channel Angular Pressing and Creep in Ultrafine-Grained Aluminium and Its Alloys[J]. Intech, 2012. 